\title{
Vontade geral, natureza humana e sociedade democrática justa. Rawls leitor de Rousseau
}

\author{
Denilson Luis Werle 1 \\ dlwerle@yahoo.com.br \\ Universidade Federal de Santa Catarina, Florianópolis, Santa Catarina, Brasil
}

resumo 0 artigo apresenta a interpretação feita por Rawls da obra de Rousseau, destacando as afinidades entre Rousseau e a tese central da tradição do liberalismo político: a primazia da justiça sobre o bem. Apresenta-se a análise feita por Rawls de dois conceitos que aproximam Rousseau do liberalismo político: a concepção normativa de natureza humana e o conceito de vontade geral, interpretada como razão pública deliberativa.

palavras-chave John Rawls; Rousseau; vontade geral; natureza humana; razão pública; justiça

Dentre os diversos ramos da filosofia, as obras de filosofia política parecem ser as que mais se ressentem da influência do tempo histórico e do espaço social em que foram desenvolvidas. As marcas dos problemas específicos, de certas ideias morais e do vocabulário conceitual próprios de uma época parece que se cravam nelas de forma indelével. Daí a pergunta frequente de leitores ávidos por respostas aos problemas políticos contemporâneos: para além da boa formação acadêmica, por que e como ler os clássicos da filosofia política? Em que sentido eles ainda podem ser "atuais"? Sem a pretensão de querer responder esse tipo de questão, pretendemos sugerir aqui um modo de torná-la mais legível por meio da apresentação da leitura que um filósofo político contemporâneo, John Rawls - sem dúvida um dos filósofos políticos mais expressivos do século XX - faz da obra de um clássico da filosofia política moderna: Jean-Jacques Rousseau. Nessa apresentação sigo a sugestão feita por 
Calvino, uma de suas várias indicações de por que ler os clássicos em geral: "para poder ler os clássicos temos de definir 'de onde estão sendo lidos', caso contrário tanto o livro quanto o leitor se perdem numa nuvem atemporal" (CALVINO, 1993, p.14). Essa sugestão de leitura me parece proveitosa para entender como Rawls interpreta a obra de Rousseau. Rawls faz uma leitura da obra completa de Rousseau, interpretando as questões e propósitos principais do projeto crítico-normativo de Rousseau. A obra de Rousseau é situada no rol dos clássicos fundadores da tradição do liberalismo político, com um texto que ainda fala para nós com uma voz relevante. Para Rawls, não se trata de ler Rousseau como se fosse uma relíquia antiquada ou como mestre pensador, mas como alguém que pode ser lido e relido com proveito, como fonte de reflexão sobre problemas e questões contemporâneas que assolam as democracias constitucionais. Para além da leitura criteriosa dos textos, Rawls estabelece com a obra de Rousseau um campo de interlocução sobre os fundamentos normativos e as possibilidades reais de uma sociedade justa e estável. A interpretação que Rawls faz de Rousseau está, portanto, profundamente vinculada com as questões e a estrutura argumentativa do próprio projeto ralwsiano de fundamentação de uma concepção de justiça para as democracias constitucionais, desenvolvido principalmente em Uma teoria da justiça (1971) e no Liberalismo Político (1993). Partindo dessa hipótese de leitura, apresento inicialmente a idéia principal do liberalismo político - a prioridade da justiça sobre o bem para, em seguida, ver como Rawls encontra essa ideia já presente in nuce na obra de Rousseau, particularmente na ideia normativa de natureza humana e no conceito de vontade geral, a primeira apresentada sobretudo no Discurso sobre a origem e os fundamentos da desigualdade entre os home$n s$, mas também presente de modo fundamental na justificação racional dos princípios do direito político desenvolvidos no Contrato Social.

\section{A ideia principal do liberalismo político de Rawls}

Rawls considera as idéias e objetivos centrais da sua teoria da justiça como equidade "como os de uma concepção filosófica da justiça para 
uma democracia constitucional”. A esperança de Rawls (RAWLS, 2002, p. xiii-xiv) "é a de que a justiça como equidade pareça razoável e útil, ainda que não totalmente convincente, para uma grande gama de orientações políticas ponderadas e, portanto, expresse o núcleo comum da tradição democrática". Um dos pressupostos da teoria de Rawls é o de que tem de haver um vínculo necessário entre a justiça e a estrutura básica de uma sociedade democrática. Uma das tarefas fundamentais da filosofia política é construir e justificar uma concepção de justiça que possa servir como uma base pública de justificação para acordos políticos entre cidadãos sobre as questões políticas fundamentais que dizem respeito aos seus direitos e deveres uns com os outros como livres e iguais e membros plenamente autônomos de uma comunidade política e à distribuição dos benefícios e encargos resultantes da cooperação social voltada para vantagens mútuas de todos. É importante considerar que Rawls não pretende elaborar uma concepção moral abrangente da justiça que fosse aplicável a um amplo leque de questões práticas, desde juízos morais quotidianos até problemas mais amplos da relação moral, política e direito. Seu propósito é mais limitado: "o objeto primário da justiça é a estrutura básica da sociedade, ou mais exatamente, a maneira pela qual as instituições sociais mais importantes distribuem direitos e deveres fundamentais e determinam a divisão de vantagens decorrentes da cooperação social"'(RAWLS, 2002, p. 8). ${ }^{2}$

A teoria da justiça de Rawls pretende fornecer um conjunto de princípios capaz de fornecer um ponto de vista comum a partir do qual reivindicações conflitantes dos cidadãos possam ser julgadas. A concepção da justiça como eqüidade oferece um padrão pelo qual se devem avaliar os aspectos da estrutura básica quando questões políticas fundamentais estão em jogo. ${ }^{3}$ Este padrão não deve ser estendido para os princípios que definem outras virtudes morais das pessoas. Trata-se, portanto, de um padrão voltado paras as principais instituições da sociedade, e apenas indiretamente para os indivíduos, à medida que estes vivem e levam adiante seus planos de vida sob as regras públicas estabelecidas por aquelas instituições.

O alcance limita-se à formação de um juízo político sobre dois tipos de problemas, que se referem a duas "circunstâncias da justiça" numa sociedade democrática: (a) questões de justiça distributiva que decorrem 


\section{4}

do problema da escassez moderada e referem-se ao modo de estabelecer os termos eqüitativos que determinam a partilha dos encargos e beneficios decorrentes da cooperação social. Estas questões não podem ser resolvidas pelo simples jogo do livre mercado, mas através de princípios substantivos de justiça aplicados à estrutura básica da sociedade. (b) questões da tolerância decorrente do fato do pluralismo das formas de vida culturais e dos planos de vida individuais. Os princípios de justiça são necessários não apenas para especificar termos eqüitativos de cooperação social, mas também para especificar os direitos e deveres de cidadãos que além de perseguirem interesses e planos de vida diferentes, estão também profundamente divididos entre si por uma diversidade de doutrinas filosóficas, religiosas, morais e política abrangentes.

A aposta de Rawls é que as idéias da moralidade política liberal conseguem oferecer respostas mais aceitáveis para as questões políticas fundamentais do que aquelas oferecidas pelo utilitarismo, predominante na filosofia política e moral moderna. ${ }^{4}$ Contra o utilitarismo, Rawls defende a prioridade da justiça frente ao bem.

A tese da prioridade da justiça sobre o bem pode ser entendida de duas maneiras. A primeira consiste em defender a idéia normativa da inviolabilidade da pessoa, geralmente expressa por um conjunto de direitos individuais fundamentais. A autonomia dos indivíduos não pode ser violada por considerações coletivas de bem-estar social, do bem comum ou outro fim coletivo. ${ }^{5}$ Isso, porém, não significa que Rawls seja um defensor da liberdade negativa ou exclusivamente da autonomia privada. O objetivo da justiça é assegurar as condições sociais, políticas e jurídicas indispensáveis ao exercício da autonomia plena dos cidadãos considerados como pessoas morais livres e iguais, o que implica considerar o exercício da liberdade em todas as suas dimensões: como autorealização ética, autonomia moral e autodeterminação política. O conteúdo moral do liberalismo político consiste numa lista de direitos e liberdades básicas iguais (liberdades políticas de participação e deliberação, liberdades civis de livre pensamento e associação; igualdade de oportunidades, liberdade de movimento, integridade da pessoa, o direito à propriedade pessoal, as liberdades abrangidas pelo rule of law); a prioridade dessas liberdades e a garantia de que todos os membros da sociedade tenham meios materiais adequados para fazer uso desses direitos e liberdades. ${ }^{6}$ 
A segunda maneira de entender a tese da prioridade da justiça sobre o bem consiste no princípio da neutralidade de justificação do Estado ou à neutralidade ética do direito frente às concepções particulares do bem e as doutrinas abrangentes. Não se trata aqui, evidentemente, da noção de um Estado liberal mínimo, com pouca presença na sociedade. Não se trata de uma neutralidade dos efeitos, mas sim de uma neutralidade de justificação no sentido de que, em uma sociedade marcada pelo fato do pluralismo, os princípios de justiça que devem regular a vida em comum não podem se apoiar em qualquer concepção particular de vida boa ou em doutrinas morais, filosóficas e religiosas abrangentes. ${ }^{7}$ Uma vez que os princípios da justiça para a estrutura básica estabelecem uma série de limites que restringem o desenvolvimento dos planos de vida individuais e as formas de vida culturais, estabelecendo normas e regras que devem ser obedecidas obrigatoriamente por todos, o que a tese da prioridade do justo sobre o bom exige é que os princípios de justiça devem ser justificados por meio de razões que todos os cidadãos, imersos em eticidades diferentes, poderiam aceitar (ou pelo menos por razões que ninguém poderia razoavelmente rejeitar), independentemente do recurso à coerção. "A idéia norteadora é que os princípios da justiça para a estrutura básica da sociedade são objeto do consenso original. São esses princípios que pessoas livres e racionais, preocupadas em promover seus próprios interesses, aceitariam numa posição inicial de igualdade como definidores dos termos fundamentais de sua associação"(RAWLS, 2002, p. 12).

Para configurar a forma desse acordo Rawls articula a moralidade política liberal num procedimento de justificação denominado posição original de deliberação sob o véu de ignorância. Trata-se de um procedimento de teste para escolha de princípios de justiça. Os princípios da justiça são objetos de um acordo alcançado pelos indivíduos sob uma posição original de deliberação na qual os princípios são escolhidos conforme as restrições razoáveis de um véu de ignorância, que garante que ninguém seja favorecido ou desfavorecido na escolha dos princípios pelo resultado do acaso natural ou pela contingência das circunstâncias sociais. ${ }^{8}$

Além dessa simetria das relações mútuas, assegurada pelo véu de ignorância, a posição original é eqüitativa entre as partes consideradas como pessoas morais livres e iguais. Quando menciona a idéia de pessoa moral, Rawls refere-se a "alguém que pode ser um cidadão plenamente 
cooperativo da sociedade ao longo de uma vida completa"(RAWLS, 1992, p. 37). Trata-se de privilegiar uma concepção de pessoa que seja adequada à idéia mais fundamental de sociedade entendida como sistema eqüitativo de cooperação social entre cidadãos como livres e iguais. Assim, para Rawls (2000, p. 37) “a idéia intuitiva básica é a de que, em virtude do que podemos chamar suas capacidades morais, e das capacidades da razão - o pensamento e o juízo, associados a essas capacidades dizemos que as pessoas são livres. E em virtude de possuírem essas capacidades em grau necessário a que sejam membros plenamente cooperativos da sociedade, dizemos que as pessoas são iguais". As pessoas são iguais no sentido de que "se consideram reciprocamente como tendo o direito ao igual respeito de determinar e de avaliar publicamente, a partir da reflexão justa, os princípios de justiça pelos quais a estrutura básica da sociedade vai ser governada (RAWLS, 1980, p. 521). ${ }^{9}$ E as pessoas são livres, e reconhecem reciprocamente a liberdade um do outro, de diferentes formas: são livres para realizarem reflexivamente suas concepções do bem; reconhecem um ao outro como fontes de pretensões válidas; e reconhecem um ao outro como pessoas responsáveis por seus fins ou concepções do bem (RAWLS, 2000, p. 543-544).

Em virtude da idéia de sociedade como sistema eqüitativo de cooperação social, Rawls pressupõe a pessoa moral como dotada com duas capacidades: a de ter um senso de justiça e a ter uma concepção do bem. O senso de justiça é a capacidade de entender, de aplicar e de agir a partir de uma concepção pública de justiça que caracteriza os termos eqüitativos da cooperação social. A capacidade de concepção do bem é a capacidade da pessoa de formar, de revisar e racionalmente perseguir uma concepção da vantagem racional, ou do bem.

Nessas duas capacidades revela-se também a tese da primazia do justo sobre o bem, só que agora sob a forma da primazia do razoável sobre o racional. O termo "razoável” é usado por Rawls para caracterizar diferentes noções: fala-se de pluralismo razoável, doutrinas abrangentes razoáveis, sistema de cooperação social razoável, concepção política razoável, e pessoas razoáveis, e assim por diante. ${ }^{10} \mathrm{~A}$ idéia é a mesma que está presente na tese da prioridade do justo sobre o bem: o razoável tem primazia sobre o racional, mas ambas são idéias complementares, e uma não pode ficar sem a outra. Segundo Rawls, "o razoável pressupõe e 
subordina o racional. Ele define os termos justos da cooperação aceitáveis a todos no interior de algum grupo de pessoas identificáveis separadamente, cada uma delas possuindo e exercendo os dois poderes morais. Todos têm uma concepção do seu bem que define sua vantagem racional, e cada um tem um senso de justiça normalmente efetivo; a capacidade de honrar os termos justos da cooperação. O razoável pressupõe o racional, pois, sem as concepções do bem que movem os membros do grupo, não há lugar para a cooperação social nem para as noções do direito e da justiça, ainda que tal cooperação realize valores que vão além do que as concepções do bem assumem em particular. $O$ razoável subordina o racional porque seus princípios limitam, e na doutrina kantiana, limitam absolutamente, os fins últimos que podem perseguir" (RAWLS, 1980, p. 530).

Rawls acentua essa diferença e complementaridade entre o razoável e o racional para ressaltar que a teoria da justiça não pode ser interpretada como derivando uma concepção de justiça a partir de um conceito de racionalidade instrumental, moralmente neutro. A justiça como eqüidade não é uma versão da teoria da escolha racional: o razoável não pode ser derivado do racional. Para marcar bem esta distinção, Rawls afirma: "outra diferença básica entre o razoável e o racional é que o razoável é público de uma forma que o racional não é. Isso significa que é pelo razoável que entramos como iguais no mundo público dos outros e dispomo-nos a propor, ou aceitar, conforme o caso, termos eqüitativos de cooperação com eles. Esses termos, apresentados como princípios, especificam as razões que devemos compartilhar e reconhecer publicamente uns perante os outros como base de nossas relações sociais” (RAWLS, 2000, p. 97).

É importante lembrar que a posição original não é concebida como uma situação histórica real ou como uma condição primitiva da cultural. Ela é um artificio de representação, "uma situação hipotética que visa reunir num procedimento de justificação que sintetiza todos os requisitos da razão prática e mostra como os princípios de justiça resultam dos princípios da razão prática conjugados às concepções de sociedade e pessoa, também elas idéias da razão prática" (RAWLS, 2000, p. 134). Ela formaliza o ponto de vista moral imparcial que possibilita a escolha de princípios para julgar questões política fundamentais. Trata-se de um procedimento de teste para escolha de princípios. 
O uso do modelo do contrato para formalizar o ponto de vista moral imparcial agrada a Rawls por duas razões. Primeiro, permite entender a justiça como equidade como expressão do conceito kantiano de autonomia (cf. o artigo de MELO, na presente edição). Para Rawls, o principal objetivo de Kant foi o de aprofundar e justificar a idéia de autonomia em Rousseau: a liberdade consiste em agir de acordo com uma lei que nós estabelecemos para nós mesmos. E isso, para Rawls, “conduz não a uma moralidade de comando austero, mas sim a uma ética de auto-estima e respeito mútuo. A posição original pode, então, ser descrita como uma interpretação procedimental da concepção kantiana de autonomia, e do imperativo categórico, dentro de uma teoria empírica"(RAWLS, 2002, p. 281). Segundo, apesar dos vários usos da palavra contrato, a linguagem do contrato traz em si as idéias de aceitabilidade razoável e de publicidade dos princípios de justiça. A vantagem da linguagem do contrato é que ela transmite a idéia de que princípios da justiça podem ser concebidos como princípios que seriam escolhidos por pessoas racionais colocadas sob determinadas restrições procedimentais razoáveis, e que assim as concepções da justiça tem a seu favor uma pretensão de aceitabilidade racional, isto é, podem ser explicadas e justificadas publicamente. No modelo do contrato as partes consideram que estão escolhendo princípios para uma concepção comum e compartilhada da justiça.

Em suma, a tese central do liberalismo é da que uma sociedade justa ou um regime legítimo é aquele no qual as instituições políticas, jurídicas e sociais possam ser justificadas a todos os cidadãos por meio de sua razão (WALDRON, 1987). Por aceitar e afirmar o pluralismo, não rejeitando ou questionando a importância da religião e das tradições, o liberalismo político insiste que as exigências e obrigações políticas impostas pela estrutura básica da sociedade devam ser justificadas à razão e ao juízo de todos os cidadãos. Essa tese central do liberalismo político desdobrase em outros conceitos fundamentais da teoria de Rawls, como o de equilíbrio reflexivo, de consenso sobreposto,de razão pública e o princípio liberal de legitimidade política, que analisamos noutra ocasião (cf. WERLE, 2008).

A partir dessas observações sobre algumas ideias básicas presentes no liberalismo político podemos compreender melhor a afirmação de Rawls de que a justiça como equidade retoma a tradição do contrato social, tal 
como expressa em Locke, Rousseau e Kant. Não se trata, é claro, de retomar in toto a tradição do direito natural. Existe uma diferença de pressupostos na estrutura da argumentação e no vocabulário conceitual. Por exemplo, para Rawls não se coloca em nenhum momento o problema da passagem de um suposto estado de natureza para a sociedade civil - não se coloca para Rawls a questão da origem legítima do poder e do Estado -, como tampouco pressupõe alguma forma de direito natural prévio, derivado da lei divina, da razão ou da natureza humana. A preocupação é elevar a um nível maior de abstração a ideia do contrato social: formalizar um ponto de vista imparcial para escolha de princípios para a estrutura básica de uma democracia constitucional já consolidada.

Para Rawls, a exigência de uma justificação pública que recorra à razão teórica e prática de cada cidadão vincula o liberalismo político à tradição do contrato social, à ideia de que uma ordem política legítima deve ser fundamentada no consentimento racional dos cidadãos. O objetivo de uma justificação contratualista é mostrar que cada membro da sociedade tem uma razão suficiente para concordar com essa ordem, reconhecendo sua normatividade, desde que os demais cidadãos também o façam. As razões que conferem legitimidade têm de ser públicas, invocadas do ponto de vista imparcial de cada pessoa razoável e racional. É justamente essa ideia básica e seus conceitos adjacentes que Rawls vai encontrar na tradição do constitucionalismo democrático, que tem no contrato social uma de suas mais vigorosas expressões.

Parece bastante evidente o vínculo do liberalismo político com autores como Locke e Kant, costumeiramente atrelados à defesa das liberdades pessoais básicas de indivíduos autônomos e são filósofos muito presentes (principalmente Kant) na própria teoria da justiça como equidade de Rawls. Mas não fica tão evidente a relação entre o liberalismo político de Rawls e a obra de Rousseau, pouco citado por Rawls. Além disso, não poucas vezes (talvez injustamente) Rousseau foi lido como inimigo da liberdade pessoal e da sociedade aberta, e sua noção de vontade geral e soberania foi vista como precursora de regimes totalitários.Vejamos como Rawls consegue demonstrar algo não muito usual: Rousseau como um dos fundadores da tradição do liberalismo político. O texto básico para isso são suas aulas sobre Rousseau proferidas nos cursos de filosofia política moderna, oferecidos em Harvard na metade 
dos anos 60 até os 90, e publicados recentemente como Lectures on the History of Political Philosophy (RAWLS, 2007). ${ }^{11}$

\section{Rousseau crítico da modernidade}

Segundo a interpretação de Rawls, Rousseau está primeiramente preocupado em fazer um diagnóstico crítico de sua época, particularmente de suas vastas e profundas desigualdades de riqueza, poder e status. Porém, o diagnóstico já é feito a partir de um critério normativo que encontra expressão numa ideia normativa de natureza humana - das características essenciais da pessoa moral e de suas capacidades - e é complementada com a noção de vontade geral, base da perspectiva emancipatória desenvolvida no Contrato Social. De modo a indicar o pano de fundo do problema que ocupa Rousseau no Contrato Social, Rawls se propõe a primeiro analisar o Segundo Discurso.

Nessa interpretação, Rawls cerra fileiras com aqueles que vêem uma unidade sistemática entre o Rousseau crítico, realista e, até certo ponto, "pessimista" em relação às realizações da modernidade, e o Rousseau mais normativo, teórico da utopia realista de uma sociedade justa. Ao contrário de leitores apressados, que levados pelo vigoroso estilo literário e frases enfáticas de Rousseau, vêem-no como um escritor retórico, confuso e inconsistente, Rawls acredita que as ideias de Rousseau são profundas e coerentes; sem dúvida, há mudanças de estilo e algumas contradições superficiais, mas a estrutura de pensamento como um todo se mantém coesa numa visão crítico-normativa da sociedade. Muito mais profundo do que outros autores contratualistas, como Hobbes e Locke, aos olhos de Rawls Rousseau é um "crítico da cultura e da civilização: busca diagnosticar o que considera como os males mais profundamente enraizados na sociedade contemporânea e retratar os vícios e misérias que ela provoca em seus membros. Rousseau espera explicar porque esses males e vícios surgem, e descrever a estrutura básica de um mundo político e social no qual não estariam presentes" (RAWLS, 2007, p. 192).

A fim de mostrar essa unidade, Rawls divide os escritos de Rousseau em três grupos: 1. os de diagnóstico da modernidade e de crítica ao iluminismo, que abrangem o Primeiro e Segundo Discurso e a Carta a 
d'Alembert sobre o teatro. Rawls se dedica a uma análise mais pormenorizada do O Segundo Discurso, visto como um diagnóstico das origens da desigualdade, da opressão política e dos demais vícios sociais da sociedade humana; é sombrio e pessimista; 2. Esse lado sombrio é contrabalançado com os textos construtivos nos quais Rousseau descreve seu ideal de uma sociedade política justa. A Nova Heloísa, Contrato Social e Emílio. O Contrato Social é a descrição dos princípios básicos de uma sociedade plenamente justa e plausível, ao mesmo tempo estável e feliz. Neste sentido, trata-se de "uma utopia realista" (RAWLS, 2007, p. 193); 3. Num terceiro grupo, apenas indicado, mas não analisado por Rawls, estão os textos autobiográficos (Confissões, Diálogos: Rousseau juíz de JeanJacques; Devaneios de um caminhante solitário) que são vistos como obras importantes para a ênfase moderna na integridade e autenticidade, para os esforços de compreender a si mesmo, de superar a alienação, de viver por si mesmo e não segundo a opinião dos outros. São uma parte importante para justificar a ênfase na liberdade de pensamento e de consciência, portanto, também são precursores de uma das preocupações básicas do liberalismo político.

Em seu comentário ao Segundo Discurso Rawls segue passo a passo a "explicação" que Rousseau fornece da história da humanidade começando com o primeiro estágio do estado de natureza e terminado com a fundação da sociedade civil desigual e da autoridade política despótica. Faz uma exposição das mudanças históricas na cultura e na sociedade e mostra como Rousseau vincula as hostilidades e vícios da civilização ao aumento na desigualdade no poder político, nas posições sociais e na riqueza e propriedade, com o estabelecimento da lei e do direito de propriedade, a desigualdade econômica entre ricos e pobres; a instituição da magistratura (poderosos e fracos) e a mudança do poder legítimo em poder arbitrário (senhor e escravos). Com a descrição dos váios estágios da sociedade humana e o caráter não necessário dessas mudanças, Rousseau quer demonstrar que "o homem é naturalmente bom e que é através das instituições sociais que nos tornamos maus. Todavia, quando olhamos para os detalhes de sua explanação do desenvolvimento da cultura e da organização social e o papel que nossas várias faculdades desempenham nesse processo - especialmente nossa razão, imaginação e autoconsciência parece inevitável que surjam os males sociais e vícios individuais conde- 
nados por Rousseau" (RAWLS, 2007, p. 197). Contudo, não há inevitabilidade na história narrada por Rousseau - afinal não há uma teleologia na história (RAWLS, 2007, p. 201ss). O que Rousseau descreve é toda a ambigüidade do desdobramento da sociabilidade humana.

Para Rawls, Rousseau descreve dois processos simultâneos: por um lado, a realização gradual de nossa perfectibilidade, isto é, nossa capacidade para realizações progressivas e refinamentos nas artes e ciências, e a invenção de instituições e formas culturais ao longo do tempo; por outro lado, o aumento de nossa alienação uns dos outros numa sociedade dividida por desigualdades crescentes (RAWLS, 2007, p.204).É esse diagnóstico das patologias da sociabilidade humana e dos potenciais de emancipação inscritos na natureza humana que importa a Rawls, diagnóstico que mostra as circunstâncias e a necessidade da justiça - por que não podemos abdicar de uma ideia de justiça - bem como a possibilidade real de superação das patologias.

Fundamental para Rawls é a concepção de homem natural que orienta o diagnóstico crítico de Rousseau. Rawls elenca todas as características do homem natural: o amour de soi e amor próprio, a compaixão ou a piedade, o livre arbítrio e a perfectibilidade, todas importantes não apenas para descrever a degeneração dos homens, mas também para pensar a realização e a estabilidade da sociedade justa projetada no Contrato Social.

Dentre essas características, Rawls dedica uma atenção especial à noção de amor próprio. Seguindo muito de perto uma interpretação de Kant, Rawls sugere que existem duas formas de amor próprio: a forma natural, que se refere a "uma forma específica de preocupação consigo mesmo (self-concern) que surge somente em sociedade. É a preocupação natural por uma posição segura em relação aos outros e envolve a necessidade de uma aceitação igual” (RAWLS, 2007, p. 198). Essa forma natural expressa nossa natureza social, nossa pertença a um sistema de interdependência e de cooperação social: expressa um anseio de igualdade consistente com a reciprocidade e o reconhecimento mútuo. ${ }^{12}$ Ao lado dessa forma natural, existe a forma pervertida e patológica do amorpróprio, que, estimulada pela razão, imaginação e autoconsciência, leva ao surgimento dos vícios, da vaidade, orgulho e arrogância, de desejo de ser superior e de dominar os outros e de ser admirado por eles, exaustivamente descritos por Rousseau. 
Para Rawls temos de aceitar essa interpretação alargada do amorpróprio para entender o próprio anseio por igualdade - a inclinação para adquirir um valor na opinião dos outros é originalmente um desejo por igualdade - e a viabilidade do projeto de uma sociedade política justa: razão e consciência não são suficientes para a realização da sociedade justa. Para Rawls, o amor próprio em sentido natural fornece uma das bases psicológicas para a realização do ideal de uma sociedade justa (RAWLS, 2007, p. 200) A outra estaria no desejo racional de ser livre, também imanente à natureza humana. Dadas as linhas gerais do diagnóstico crítico de Rousseau, Rawls analisa o problema que está na base do contrato social.

\section{Contrato Social: pressupostos normativos e o conceito de vontade geral.}

A tese que orienta a diagnóstico crítico da sociedade humana é a da bondade natural dos homens: "os homens são naturalmente bons e as instituições sociais os modificam". Dessa tese resultam aos olhos de Rawls duas proposições básicas do Contrato Social: a) as instituições políticas e as condições sociais desempenham uma influência predominante sobre o desenvolvimento moral das pessoas e (b) existe um esquema de instituições políticas possível e razoavelmente plausível que satisfaça tanto os princípios do direito político quanto as exigências de estabilidade institucional e de felicidade humana: considerar os homens como são e as leis como podem ser.

O Contrato Social é interpretado por Rawls como sendo uma utopia realista, que descreve os princípios do direito político para uma sociedade justa estável e praticável. A pretensão realista do projeto normativo de Rousseau está enunciada logo no início livro primeiro: "quero indagar se pode existir, na ordem civil, alguma regra de administração legítima e segura, tomando os homens como são e as leis como podem ser" (ROUSSEAU, 1973, p. 27). O grande desafio de Rousseau é encontra alguma unidade a partir da pluralidade dos indivíduos. Para assegurar tanto a estabilidade quanto a felicidade e a justiça, tem de ser alcançado um ajuste entre o que o direito legítimo (razoável) permite e o que os 


\section{4}

interesses particulares (racional) prescrevem aos indivíduos. Se não houver isso, o justo e o útil entram em conflito e não se torna possível um regime estável e justo. Nesse ajuste, os conceitos de pacto social, vontade geral e natureza humana desempenham papel chave.

Como interpretar a intenção realista de Rousseau? O que significa considerar os homens como eles são? "Tomar os homens como eles são" não significa considerá-los como eles são aqui e agora, com todos os seus vícios e hábitos de uma civilização corrupta, como foram descritos no Segundo Discurso - erro que Rousseau censura na descrição que Hobbes faz dos homens e de suas relações no estado de natureza. Significa sim considerá-los segundo os princípios e propensões naturais do homem natural, que incluem a capacidade de uma vontade livre (para identificar razões válidas e agir à luz delas) e a perfectibilidade (a potencialidade para o auto-aperfeiçoamento por meio do desenvolvimento histórico de nossas faculdades no seio da cultura. Também devemos considerar o amor de si e o amor próprio (no sentido alargado) como aspectos psicológicos básicos de nossa natureza (RAWLS, 2007, p. 215). Esses princípios mais fundamentais da psicologia humana são os que possibilitam a formação de nosso caráter, que permitem explicar que tipo de identidade as pessoas vão adquirindo sob dadas condições históricas, políticas e sociais. São também fundamentais para explicar a noção de pacto social e de vontade geral. ${ }^{13}$

Para Rawls (2007, p. 215), o contrato social de Rousseau tem de responder a quatro questões: 1) como são justificados os princípios do direito político e da justiça? como é estabelecida a correção desses princípios? 2) quais instituições sociais e políticas realizam de forma mais efetiva esses princípios e mantêm a sociedade estável ao longo do tempo? 3) de que modo as pessoas aprendem os princípios do justo e adquirem a motivação de agir a partir deles e afirmar a concepção política a qual eles pertencem? Quais as forças psicológicas que ajudam a manter a estabilidade e como elas são adquiridas e aprendidas (psicologia moral)? 4) como pode surgir uma sociedade que realiza esses princípios do direito e da justiça (origens e o processo por meio do qual a sociedade do pacto social pode surgir)? ${ }^{14}$

A análise do pacto social e do conceito de vontade geral é introduzida por Rawls como resposta às duas primeiras questões. Rawls traduz o problema do pacto social em Rousseau usando o vocabulário próprio da 
teoria da justiça como eqüidade. A idéia central do pacto é a de que podemos nos sentir vinculados e obrigados a uma autoridade política quando esta puder surgir de nosso consentimento como pessoas livres e iguais, razoáveis e racionais (RAWLS, 2007, p. 216). O pacto social especifica os termos da cooperação social que devem se refletir em instituições sociais e político-jurídicas. Rawls discute uma série de pressupostos presentes no pacto social de Rousseau: a) aqueles que cooperam na sociedade pretendem realizar seus interesses fundamentais, seu bem razoável e racional vinculados ao amor de si e ao amor próprio; b) as pessoas que cooperam tem de realizar seus interesses sob as condições de interdependência social com os outros: a cooperação social na forma de instituições sociais e políticas é tanto inevitável quanto vantajosa. A interdependência social é parte de nossa condição; c) todas as pessoas têm uma capacidade igual e um interesse geral na liberdade, isto é, a capacidade de ter uma vontade livre e para agir à luz de razões válidas, bem como um interesse em agir a partir de seus próprios juízos sobre o que acham que é o melhor à luz de seus objetivos e interesses particulares; d) todas as pessoas têm uma faculdade igual para um senso político da justiça e um interesse em agir de acordo com ele: a capacidade de entender, aplicar e agir a partir dos princípios do pacto social. (RAWLS, 2007, p. 219).

Segundo esses pressupostos, que Rawls vai indicando passo a passo em passagens textuais do Contrato Social, o problema do pacto social em Rousseau é o seguinte:"como, sem sacrificar nossa liberdade, unir-se com outros para assegurar a satisfação de nossos interesses fundamentais e assegurar as condições para o desenvolvimento e exercício de nossas capacidades?" (RAWLS, 2007, p. 220). A resposta de Rousseau seria: dado o fato da interdependência social e a necessidade e a possibilidade de uma cooperação social mutuamente vantajosa, a forma da associação política deve ser arranjada de tal modo que seja razoável e racional para pessoas livres e iguais darem seu consentimento de modo que "cada um, unindose a todos, só obedece, contudo, a si mesmo, permanecendo assim tão livre quanto antes" (ROUSSEAU, 1973, p. 38). Para existir uma tal associação política entre livres e iguais tem de estar disponível um ponto de vista comum a partir do qual os cidadãos podem avaliar a legitimidade de seus interesses particulares e resolverem seus conflitos e divergências. Isso nos conduz a análise da vontade geral e do bem comum. Novamente a 
noção de natureza humana e seus interesses fundamentais desempenhará papel essencial nessa análise. ${ }^{15}$

O que fornece a justificação da autoridade política na sociedade sobre questões de justiça política é bona fide expressão da vontade geral. A vontade geral é expressa em leis políticas fundamentais relativas aos fundamentos constitucionais e à justiça básica. Mas como entender a vontade geral? Nesse ponto Rawls dá uma interpretação "racionalista" da vontade geral, interpretando-a como razão pública, procurando livrá-la de seu lado sentimental ("ouvir a voz da natureza no silêncio de suas paixões”) e de seus aspectos totalitários. ${ }^{16}$

No esclarecimento da vontade geral, Rawls começa caracterizando a noção de indivíduos em Rousseau. Cada indivíduo incorporado na sociedade política tem interesses particulares. Nos limites da liberdade civil, esses interesses são a base de razões válidas para agir. Cada um de nós tem uma vontade particular e vontade significa a capacidade para uma razão deliberativa (RAWLS, 2007, p. 224). O primeiro passo para evitar uma interpretação totalitária da vontade geral é admitir que a sociedade orientada pelo contrato social admite a existência legítima de uma pluralidade de interesses particulares distintos.

Claro, isso não deve nos levar a pensar que a sociedade do pacto social seja uma mera agregação dos interesses particulares das pessoas. Como dito acima, a condição essencial de uma sociedade justa é que ela tenha um ponto de vista publicamente reconhecido para lidar com suas divergências e conflitos profundos de interesses, valores e crenças - ponto de vista que deve ter a primazia sobre as vontades particulares. Esse ponto de vista está disponível quando os cidadãos compartilham publicamente uma concepção do seu bem comum, que se expressa na vontade geral. Na interpretação de Rawls, a vontade geral é uma forma de razão deliberativa compartilhada e exercida por cada cidadão como membro de um corpo corporativo, ou a pessoa pública (o corpo político) que passa a existir com o pacto social. É uma vontade distinta da vontade privada de cada um. Porém não podemos interpretá-la como sendo a vontade de uma entidade que transcende os cidadãos como indivíduos membros da sociedade. Na interpretação de Rawls são sempre os cidadãos individuais que têm a vontade geral, isto é, cada um tem a capacidade para uma razão deliberativa que, nas situações particulares e nas ocasiões apropriadas, faz 
com que os cidadãos decidam o que fazer tendo como referência sua opinião sobre o que seria melhor realizar tendo em vista seu interesse comum no que é necessário para a preservação comum e bem-estar geral, o seu bem comum. A vontade geral é plausível porque como membros da sociedade política os cidadãos compartilham uma concepção do seu bem comum, que é publicamente conhecido. A vontade geral quer realizar esse bem comum, entendido como as condições sociais que tornam possível para os cidadãos realizarem seus interesses comuns. Para Rawls, o importante é entender a vontade geral como o ponto de vista da justiça que delimita e torna possível uma base pública de justificação para realizar os interesses fundamentais dos cidadãos como membros de um sistema social de interdependência recíproca. O ponto de vista da vontade geral ainda é neutro frente às diversas concepções do bem particulares e o que ele possibilita é um forma comum de razão pública, compartilhada pelos cidadãos, que dispõem as principais instituições sociais, políticas e jurídicas de tal forma que possibilite a realização do bem comum. Trata-se de entender a vontade geral como um ponto de vista: é uma forma de razão deliberativa que cada cidadão compartilha com todos os outros cidadãos em virtude de compartilharem uma concepção de seu bem comum. E o que os cidadãos acreditam que vai realizar o seu bem comum fornece-lhes boas razões para as decisões políticas (RAWLS, 2007, p. 224-225).

Mas o que torna possível falar em bem comum considerando que existe uma pluralidade de vontades particulares? Afinal, cada forma de razão deliberativa e vontade tem seu próprio meio de identificar razões válidas para seu agir. A realização do liberalismo político não foi justamente afastar essa linguagem do bem comum, afirmando a primazia da justiça sobre o bem? Para Rawls, afirmar a primazia da justiça sobre o bem não anula a possibilidade de ver a congruência do justo e do bem. Para isso, é necessário interpretar formalmente o bem comum como sendo aquilo que realiza os interesses mais fundamentais das pessoas. Por conseguinte, para descobrir o bem comum e determinar os interesses fundamentais Rousseau teria adotado, segundo Rawls, um procedimento típico dos filósofos da tradição contratualista: "uma normalização dos interesses atribuídos às partes que vão fazer o contrato" (RAWLS, 2007, p. 226). Em Hobbes, é o interesse fundamental na auto- 
preservação, nos afetos conjugais, as riquezas e os meios de uma vida confortável [riches and the means of commodious living]. Em Locke, são a vida, as liberdades e a propriedade. Em Rousseau os interesses fundamentais são determinados por uma concepção de natureza humana e de seus interesses fundamentais e suas capacidades essenciais. Nas palavras de RAWLS (2007, p. 225): "é sua concepção de pessoa considerada em seus aspectos essenciais. Essa concepção de pessoa é uma concepção normativa e dela derivamos a enumeração de nossos interesses fundamentais. Rousseau não está olhando para as pessoas tal como elas realmente são em uma sociedade marcada pelos extremos de desigualdade entre ricos e pobres, poderosos e fracos, dos quais resulta a dominação e a subjugação. Está olhando para os seres humanos como eles são pela natureza, entendidos à luz de sua concepção de natureza. Essa natureza determina nossos interesses fundamentais”. Para Rawls, trata-se de uma concepção de pessoa como ideia normativa, que compreende as características do homem natural de Rousseau elencadas anteriormente: o amor de si e o amor próprio, a piedade, perfectibilidade e a liberdade. Dessas características derivamos nosso interesse fundamental na realização ampla da liberdade e da igualdade.

Nessa explicação da vontade geral e da natureza humana em Rousseau, temos claramente explicitada a tese da primazia da justiça sobre o bem nos sentidos explicitados no início do artigo: a sociedade justa deve privilegiar certos interesses fundamentais da pessoa, que não podem entrar no jogo da barganha política justamente por serem a expressão de nossa dignidade como pessoas morais livres e iguais. Para tanto, a sociedade justa deve ter um base pública de justificação - a vontade geral como razão pública - a qual os cidadãos podem recorrer para deliberarem sobre as questões políticas fundamentais. A vontade geral não é o ponto de vista utilitarista ou um princípio agregativo, mas sim um ponto de vista deontológico, fundado na prioridade absoluta de determinados interesses fundamentais sobre nossos interesses particulares (RAWLS, 2007, p. 230). Como um ponto de vista, trata-se de uma razão deliberativa voltada para certos tipos de questões e que admite que certos tipos de razões tenham peso na deliberação: somente razões baseadas nos interesses fundamentais que compartilhamos como cidadãos deverão contar como razões quando agimos como membros de uma assembléia 
ao promulgarmos normas constitucionais ou leis básicas. Rawls (2007, p. 231) conclui: "portanto, a partir disso fica claro que a concepção de Rousseau contém uma ideia que chamei de razão pública”. Na sociedade justa de Rousseau "todos tem o mesmo interesse fundamental em sua liberdade e em perseguir seus fins dentro dos limites da liberdade civil. Tem também uma capacidade similar para a liberdade moral - isto é, a capacidade para agir de acordo com as leis gerais que dão a si mesmos bem como a outros para a busca do bem comum. Cada um vê essas leis fundamentadas numa forma apropriada de razão deliberativa para a sociedade política, sendo essa razão a vontade geral que cada cidadão tem como membro dessa sociedade" (RAWLS, 2007, p. 247)

Rawls analisa ainda uma série de outros aspectos da vontade geral relacionando-os com o problema que ocupou o próprio Ralws no Liberalismo Político: a questão da estabilidade de uma sociedade justa entre cidadãos livres e iguais profundamente divididos entre si por concepções particulares de vida boa diferentes e muitas vezes irreconciliáveis. Aspectos sem dúvida relevantes, mas que extrapolam os limites desse artigo. Rawls acredita que também nesta questão Rousseau tem boas respostas ao mostrar como podemos reconciliar num esquema da sociedade justa a tensão entre igualdade e liberdade (ou entre a liberdade dos antigos e a dos modernos); o significado desses dois conceitos para o sentimento de auto-estima e auto-respeito e a preservação das condições de independência pessoal de modo que ninguém esteja sujeito ao poder arbitrário de outrem, das condições sociais e do acaso natural. Nisso consiste outro caráter específico da obra de Rousseau, que não temos como analisar nos limites dessa exposição.

Enfim, com suas aulas sobre Rousseau e os demais filósofos fundadores da modernidade político-jurídica, Rawls acena para a possibilidade de fazer uma história da filosofia mais frutífera cujo mérito, se houver algum, reside em mostrar que pela leitura e reflexão sobre as obras clássicas, cujas ideias estão mais ou menos presentes na cultura política pública das democracias constitucionais, podemos elaborar concepções mais profundas e mais instrutivas sobre as ideias políticas básicas que nos ajudam a esclarecer nossos juízos sobre as questões políticas fundamentais e os fundamentos normativos das instituições e políticas de uma sociedade democrática. 
1 Professor de Ética e Filosofia Política da Universidade Federal de Santa Catarina e pesquisador do Núcleo Direito e Democracia do CEBRAP

2 O conceito de estrutura básica é, como reconhece o próprio Rawls, um tanto vago. Nem sempre fica claro quais instituições ou quais de suas características deveriam ser incluídas. Numa definição aproximada, Rawls entende por instituições mais importantes "a constituição política e os principais arranjos econômicos e sociais. A proteção legal da liberdade de pensamento e de consciência, os mercados competitivos, a propriedade particular no âmbito dos meios de produção e a família monogâmica constituem exemplos das instituições sociais mais importantes". (RAWLS, 2002, p. 8).

3 Essas questões referem-se aos "elementos constitucionais essenciais" (os princípios fundamentais que especificam a estrutura geral do Estado e do processo político; as prerrogativas do legislativo, do executivo e do judiciário; o alcance da regra da maioria; os direitos e liberdades fundamentais e iguais de cidadania que as maiorias legislativas devem respeitar, tais como o direito ao voto e á participação política, a liberdade de consciência, a liberdade de pensamento e de associação, assim como as garantias do rule of law.) e "às questões de justiça básica" (a distribuição dos bens sociais básicos).

${ }^{4}$ Sobre a interpretação rawlsiana do utilitarismo, cf. \ 9 da Teoria da Justiça (RAWLS, 2002).

5 “Cada pessoa possui uma inviolabilidade fundada na justiça que nem mesmo o bem estar da sociedade como um todo pode ignorar. Por essa razão, a justiça nega que a perda da liberdade de alguns se justifique por um bem maior partilhado por todos. Não permite que os sacrificios impostos a uns poucos tenham menos valor do que o total maior das vantagens desfrutadas por muitos. Portanto, numa sociedade justa as liberdades de cidadania igual são consideradas invioláveis; os direitos assegurados pela justiça não estão sujeitos à negociação política ou ao cálculo de interesses sociais (...). Sendo virtudes primeiras das atividades humanos, a verdade e a justiça não são negociáveis” (RAWLS, 2002, p. 4).

6 Sobre isso cf. WERLE, 2008.

7 "Essa prioridade do justo em relação ao bem acaba sendo a característica central da concepção da justiça como eqüidade. Impõe critérios ao modelo da estrutura básica como um todo; esses critérios não devem gerar tendências e atitudes contrárias aos princípios de justiça [...] e devem assegurar que as instituições justas são estáveis. Assim, certos limites iniciais são estabelecidos para dizer o que é bom e quais formas de caráter são moralmente dignas, e igualmente que tipos de pessoas os seres humanos deveriam ser. Qualquer teoria da justiça estabelece alguns limites dessa natureza, isto é, os limites que se exigem para que os seus princípios primeiros possam ser satisfeitos em quaisquer circunstâncias" (RAWLS, 2002, p. 34).

8 "Entre as características essenciais dessa situação está o fato de que ninguém conhece seu lugar na sociedade, a posição de sua classe ou status social e ninguém conhece sua sorte na distribuição de dotes e habilidades naturais, sua inteligência, sua força e coisas semelhantes. Eu até presumo que as partes não conhecem suas concepções do bem ou suas propensões psicológicas”(RAWLS, 2002, p. 13). Sobre o significado mais amplo do conceito de posição original cf. também o artigo de MELO, na presente edição.

doispontos, Curitiba, São Carlos, vol. 7, n. 4, p.31-52, setembro, 2010 
9 “Essa igualdade dos cidadãos em determinar os princípios de justiça é mais fundamental do que os ideais de igualdade que são institucionalizados na estrutura básica da sociedade (por exemplo, a igualdade formal diante da lei, a igualdade de oportunidade com respeito aos poderes e cargos definidos pela estrutura básica). Ela está fundada em seu status comum como pessoas morais" (BAYNES, 1992, p. 56).

10 Sobre algumas das aplicações do par razoável-racional cf. a "Conferência II - As Capacidades dos Cidadãos e Sua Representação”de RAWLS, 2000.

11 Além de Rousseau, o livro inclui as aulas sobre Hobbes, Locke, Hume, Mill, Marx (todos considerados por Rawls como fundadores de diferentes versões do constitucionalismo democrático) e dois apêndices (sobre Sidgwick e Joseph Butler)

12 Para mais detalhes sobre essa possibilidade de interpretação do amor próprio em Rousseau, cf. NEUHOUSER, 1993, 2010.

13 Rawsl faz um pequeno excurso para explicar por que Rousseau tem essa concepção de natureza humana, esclarecendo sua controvérsia com a doutrina ortodoxa do pecado original e com Hobbes (RAWLS, 2007, p. 208-211).

14 Por uma questão de espaço, analisamos apenas a resposta a duas primeiras questões. $\mathrm{O}$ problema da relação entre vontade geral e a questão da estabilidade, as ideias de igualdade e liberdade, não serão analisados no presente artigo. Sobre isso, cf. RAWLS, 2007, p.229-247),

15 Novamente, deixaremos de lado a análise dos conceitos de liberdade (natural, civil e moral) e da igualdade (natural e moral) feitas por Rawls.

16 Rawls reconhece que "embora algumas referências à vontade geral no Contrato Social sejam obscuras, acredito que a ideia em si mesma pode ser esclarecida, e as coisas principais que Rousseau diz sobre ela são consistentes e fazem sentido" (RAWLS, 2007, p. 228).

\section{Referências bibliográficas}

CALVINO, Italo (1993). Por que ler os clássicos? Tradução de Nilson Moulin. São Paulo: Companhia das Letras.

BAYNES, K. (1992). The normative grounds of social criticism: Kant, Rawls, Habermas. New York: New York Press.

NEUHOUSER, Frederik (1993). "Freedom, dependence, and the general will”, Philosophical Review, july.

. (2010). "Roussseau and the human drive for recognition (amour proper)", in: SCHMIDT AM BUSCH, Hans-Christoph.; ZURN, Christopher F. The philosophy of recognition. Historical and contemporary perspectives. Maryland: Lexington Books, p. 21-46. 
RAWLS, John (1980). "Kantian Constructivism in Moral Theory" Journal of Philosophy, 77, p. 515-72.

(1992). "Justiça como Equidade:uma concepção política, não metafísica da justiça”, Lua Nova, n.25, p.25-59. (2000). O liberalismo político. Tradução de Dinah Azevedo. São Paulo: Ática.

(2002). Uma teoria da justiça. São Paulo: Martins Fontes. . (2007). Lectures on the history of political philosophy. Ed. por Samuel Freeman. Cambridge/Massachusetts/London: Belknap Press of Harvard University Press.

ROUSSEAU, Jean- Jacques (1973). Do contrato social. $1^{a}$ ed. São Paulo: Abril Cultural (coleção os pensadores).

WALDRON, Jeremy (1987). "The theoretical foundations of liberalism”, Philosophical Quarterly, april.

WERLE, D. (2008). Justiça e democracia: ensaios sobre John Rawls e Jürgen Habermas. São Paulo: Singular/Esfera Pública 